\title{
Investigating the Speed of Lexical Activation in the Bilinguals' L1 and L2 through Forward and Backward Translation Task
}

\author{
Saddam H.M. Issa $18 D \square$, Shyamala K.C $28 D$ \\ ${ }^{1}$ Research Scholar, Department of Linguistics, University of Mysore, India \\ 2 Professor of Language Pathology (Retd), AllSH, Mysore
}

$\triangle$ Corresponding Author: Saddam H.M. Issa, E-mail: sadgull67@gmail.com

ARTICLE INFORMATION ABSTRACT

Received: February 08, 2021

Accepted: March 04, 2021

Volume: 3

Issue: 3

DOI: $10.32996 /$ ijels.2021.3.3.4

\section{KEYWORDS}

Bilingualism, bilingual language processing, second language activation, Arabic-English

bilinguals
The relationship between lexical activation in L1 and L2 was investigated using a backward and forward translation task. Bilingual Arabic-English speakers first translated forward from L1 to L2, then backward from L2 to L1. Two groups of participants were established (high and low proficient bilinguals). The translation task included words that were being translated in both L1 and L2. The goal of the study was to see how strong the relation between $\mathrm{L} 1$ and $\mathrm{L} 2$ translation is. The findings of the study revealed that bilingual memory relations are asymmetric: translation from $\mathrm{L} 1$ to $\mathrm{L} 2$ is conceptually mediated, but the translation from $\mathrm{L} 2$ to $\mathrm{L} 1$ is lexically mediated.

\section{Introduction}

Language tends to be the most important human contact mechanism since it can be used to understand and communicate a wide variety of thoughts and emotions. It is used to share ideas and provide an accurate picture of what we see around us. Another essential function of language is to enable us to think about ourselves, our thoughts, and other people. Language for communicating involves a variety of sophisticated brain mechanisms in the bilingual's head as well as vast amounts of knowledge on the various meanings of words that make it easier to communicate thoughts.

Any language speaker has his or her own psychological dictionary or vocabulary store, from which he or she selects and uses words and responds to others' utterances (Kroll, van Hell, Tokowicz and Green, 2010). The mental lexicon refers to a language speaker's psychological representations of words, their multiple meanings, and the semantic division that indicates which group a word belongs to. The mental dictionary's arrangement of these various definitions and details is an important idea that should be researched and given further attention. Lexicon refers to a language's vocabulary, which contains words and phrases. It also contains lexemes, which are used to form words that are formed according to specific morpho-syntactic laws (Grainger and Dijkstra, 1999). As a result, a lexicon organizes a speaker's mental language in accordance with those definitions (e.g. all verbs of motion can be connected in a lexical network). A generative method generates basic and complex words based on linguistic laws.

The mental lexicon, which is a part of logical comprehension, is thought to contain a vast number of lexical entries for each word. Lexical entries are part of a word's retained knowledge and is helpful for naming, reading, and distinguishing it from similar words. This understanding of the meaning of words can be expressed in semantic characteristics. When added together, semantic characteristics are individual meaning components that include the word's full meaning. For example, to describe the word apple, you might use semantic features like peach, red, juicy, delicious, grows on trees, and so on. These characteristics include information about the corresponding word's representation, the phrase that corresponds to the word, and the meaning categorization. To understand semantic representation, a variety of theories and models have been suggested (Rosch \& Mervis,

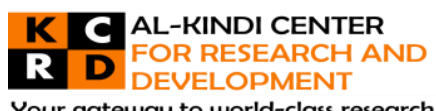

Your gateway to world-class research

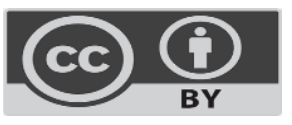

Published by Al-Kindi Center for Research and Development. Copyright (c) the author(s). This open access article is distributed under a Creative Commons Attribution (CC-BY) 4.0 license 
1975; Norman \& Rumelhart, 1975; Minsky, 1975; Smith, Shoben, \& Rips, 1974; Collins \& Quillian, 1969), which take semantic representation into account in terms of semantic characteristics as well.

The semantic characteristics for a set of concepts are normally generated by asking participants to list semantic characteristics that they think are appropriate to describe the respective concepts (e.g., for the target word 'dog,' canine, has four legs, barks, etc.). Despite the fact that words are used as stimuli in the role generation task, semantic characteristics give insight into conceptual representation when the term and conceptual knowledge are closely related. Nouns that describe concrete thoughts, abstract definitions to some extent, verbs that define behavior, and even adjectives may be used as semantic stimuli. Variables like familiarity and imageability of concepts and the number of instances of these concepts in a language all play a part in the creation of semantic characteristics.

Since these mathematical trends shape the operational principles of various proposed semantic theories and sense representation models, the mental lexicon's signature features shed light on fundamental aspects of semantic representation's nature. Semantic properties are often used to do accurate and quantitative testing of claims about the mental lexicon structure, as demonstrated by these theories and models. Many semantic representation hypotheses, such as prototype theory (Rosch \& Mervis, 1975) and exemplary theories, are also based on semantic characteristics (Smith \& Medin, 1981). The hierarchical network model of semantic memory and language representation (Collins \& Loftus, 1975), the Semantic Feature Comparison Model (Smith, Shoben \& Rips, 1974), the Featured and Unitary Semantic Space (FUSS) Model (Vigliocco, Vinson, Lewis \& Garrett, 2004), and the Vector Model of Memory (Hintzman, 1986; M) are all theories that use semantic characteristics (Hinton \& Shallice, 1991; Plaut \& Shallice, 1993).

Before the time of significant vocabulary growth begins, monolinguals and bilinguals must organize their existing vocabulary. In the previous segment, we concentrated on the organization of single words. In contrast to the indirect evidence in the word learning literature of the lexical-semantic approach developed earlier, neural and behavioural approaches provide a convergence of explicit results for the early lexical-semantic organization. Brain regions recruited for semantic treatment between 12 and 18 months of age at the early stage of language acquisition tend to increase with age (Travis et al., 2014) and in conjunction with those recruited for semantic recovery at the early stage of language acquisition, according to data from magnetoencephalography and structural magnetic resonance imaging (MRI).

\section{Methodology}

Despite the fact that translation has long been a standard pedagogical task in second language teaching, the use of the RTbased translation task as a research tool is relatively new, with the exception of Cattell (1887) and Lambert, Havelka, and Gardner (1959). Because of the task's bilingual nature, it is often used in bilingual and L2 studies. An individual is given the word and instructed to translate it into another language as soon as possible in a localization mission. In terms of the translation process, a difference is often created and manipulated. The migration of a sentence from $L 1$ to $L 2$ is referred to as forward translation. A Backward Translation is an L2-L1 localization.

The visual cue (word) will be shown on the screen during the test, and the respondent will be asked to name or translate the word using the headphones. When viewing the written form, the time allotted must be considered. Each section's hundred photos are imported into the DMDX program and displayed at random. This approach was used twice in the translation task, each time in the same manner and format. Each participant was given two different experimental sequences in each study: one with word stimuli from L1 to L2 and the other with word stimuli from L2 to L1.

\section{Result and Discussion}

\subsection{Comparison of performance of HPB \& LPB in L1 to L2 translation.}

For bilingual research, bi-directional translation tasks were created, so two lists were created: the first list of items being translated from $L 2$ to $L 1$ and the second list of items being translated from $L 1$ to $L 2$. These lists were distributed evenly among the participants, and the objects were presented in random order; each participant only had to translate each object once (from $L 2$ to $L 1$ or from L1 to L2). Participants were asked to use the English version of the word or vice versa when Arabic stimuli were introduced.

One way to compare HPB and LPB ratings in L1 to L2 conversion is to use a phrase rather than a picture and expect the subject to pronounce its equivalent in L1 or L2 based on the presented word stimulus. Participants will receive 50 words in Arabic (L1) and 50 words in English (forward translation) for translations into Arabic (backward translation) or English (forward translation) (L2). The provided stimuli are words that must be interpreted before they can be translated, which distinguishes this function from image naming. When an image is shown to a participant, he or she will be able to call it in either L1 or L2, while in the case of a translation task (word translation), if the participant does not know the meaning of the word presented and is unable to recognize it, he or she will almost certainly not be able to translate it into any of the languages. 
Bilingual people do not only comprehend texts in two languages, but they can also translate information from one language (L1) to another (L2) (forward translation) and vice versa (backward translation). A big question about this ability is that the word translating is quicker than the other; the research participant has a superior ability to translate from L1 to L2 or the other way around. The current study's key concern is whether there is a substantial gap in results between the HPB and LPB groups on the mission's forward translation state. The translation task was used to investigate lexical activation speed and accuracy under two conditions: forward translation (L1 to L2) and backward translation (L1 to L2) (L2 to L1). This segment would look at the forward translation (L1 to L2).

Statistical analysis was conducted using an independent t-test on mean RTs to determine the two classes' performance. For contrast, MRTs and ACC from L1 to L2 were used. In the first condition, the HPB group's MRT was 1390.83ms, MSE= 65.45, while the LPB group was $1699.894 \mathrm{~ms}$, MSE $=29.474$. The study found a significant interaction between the two bilinguals classes in interpreting words in $\mathrm{L} 2, \mathrm{t}(48)=-4.306, \mathrm{p}=0,001 \mathrm{0.05}$, for LI-to-L2 translation. A study of the HPB and LPB classes in forward translation showed a substantial gap in MRT and ACC in word translation in L2. The study's results are shown in charts 4.8 and 4.9 below.

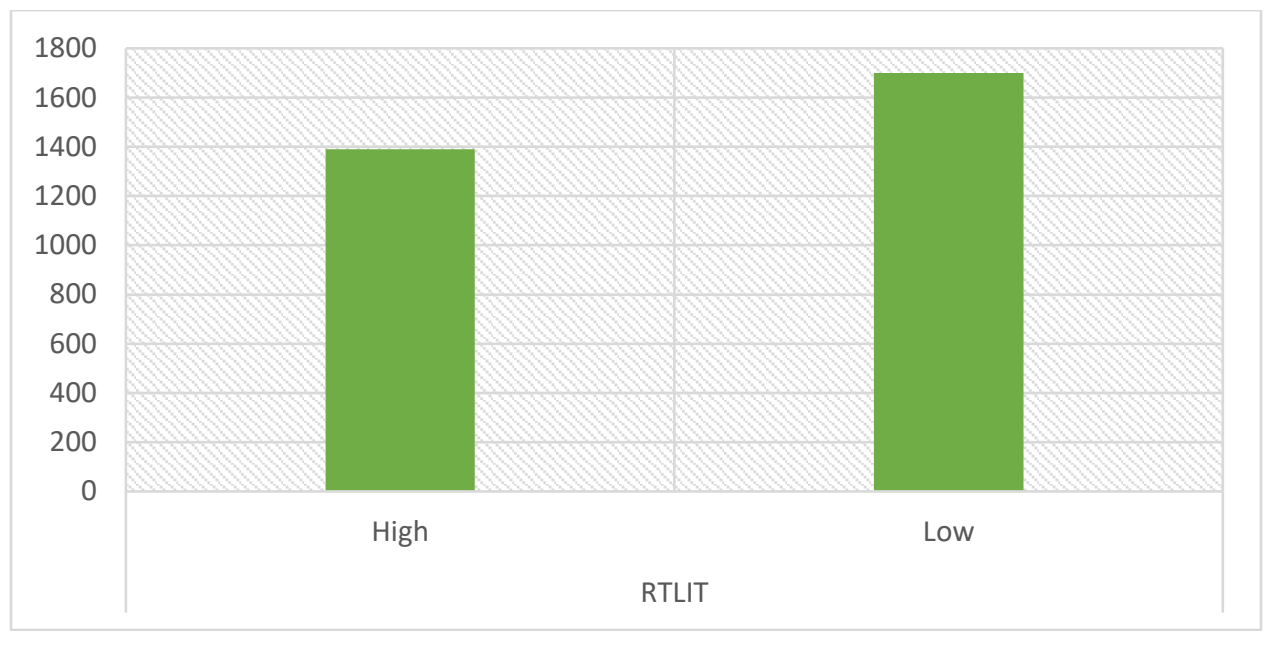

Chart 4.8.MRT of HPB \& LPB in L1 to L2 Translation.

When it came to L1-to-L2 conversion, HPB outperformed LPB. The accuracy data as a function of the translation path from L1 to $\mathrm{L} 2$ is seen in Chart 4.9. A t-test was used on the accuracy results, and it showed a significant difference in the main score between HPB and LPB, $t(48)=10.476, p=0010.05$. The HPB group outperformed the LPB group in terms of L1-to-L2 translation accuracy $(90.36 \%)(79.36 \%)$.

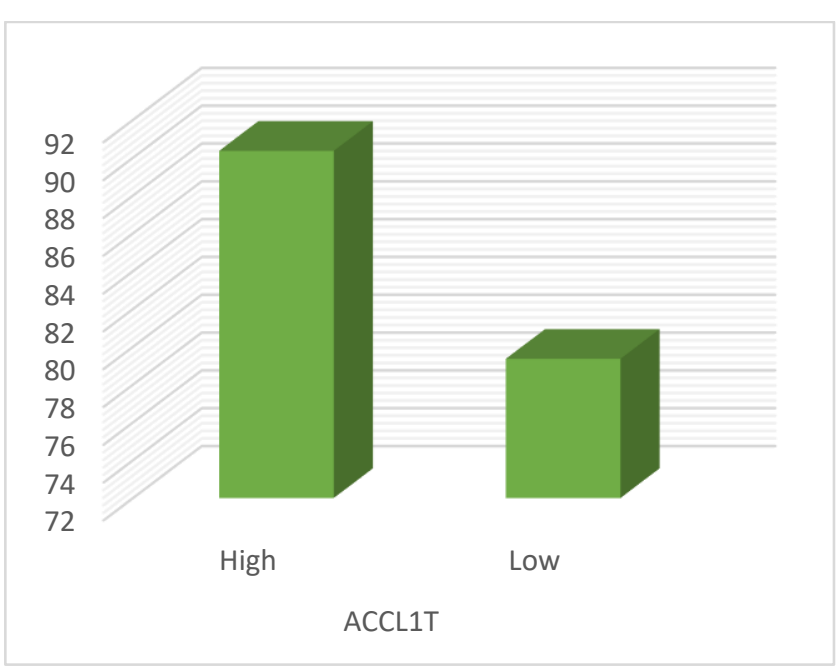

Chart 4.9. Men score (ACC) of HPB Vs LPB in L1 to L2 Translation.

The findings backed the hypothesis that the HPB group could convert from LI to L2 faster and more reliably than the LPB group, since proficiency level played such an important role in this challenge. When comparing these two classes' success in the forward 
and backward translation activities, a debate is inevitable. The findings affirm the general assertion that tasks with similar logical processing parameters take priority (e.g., Durgunoglu \& Roediger, 1987; Smith, 1991), as well as the updated hierarchical model's recommendation for differential sensitivity between the two paths of translation through semantic influences (e.g., Durgunoglu \& Roediger, 1987; Smith, 1991). (Stewart and Kroll, 1994). As a result, other factors, rather than proficiency, can be used to capture the most recent data. The only bilinguals who can reach a high success score have a high literacy level in two much-related languages or learned their L2 very early in life. From a scientific standpoint, it is important to find out which of these concepts is accurate. This is because the results cannot be viewed in terms of comparable levels of inhibition if other groups of extremely fluent bilinguals perform poorly.

The RHM model showed that bilinguals have a different lexical archive for each language vocabulary and a related semantic inventory. It is assumed that the connections between the lexical stores are weaker from L1 to L2 than the other way around. It is assumed that connections between mental representations and words in L2 are poor at first but strengthen with practice. Bilinguals are believed to be able to execute the same underlying semantic representations of both languages while practising their second language. Despite the fact that the precise form of the conceptual representations was not defined, we believe that the RHM critics spoke of abstract representations of features (Kroll, Van Hell, Tokowicz, \& Green, 2010). The model lacks how translation-equivalent terms in different languages are linked to semantic representations that are subtly different.

This result indicates that high-proficient bilinguals would be more likely to expose variations in lexical activation between them and low-proficient bilinguals (speed of response and accuracy). In L2, slower response time and less precision are assumed to reflect longer semantic integration attempts than in L1 (Hahne \& Friederici, 2001). Furthermore, two variables that must be addressed concurrently will affect the degree of semantic organization (lexical activation) in a bilingual second language: vocabulary ability (proficiency) and exposure time (Moreno \& Kutas, 2005). As a result of their poor proficiency in this request, the low proficient group's sluggish performance and low rate of correct responses are clearly seen and articulated. Furthermore, it has been claimed that high fluent bilingual lexical organization in one language allows retrieval of words in another language that are phonologically and semantically similar (Hoshino \& Thierry, 2011) or phonologically and orthographically related (e.g. Wu \& Thierry, 2010), demonstrating that bilingual language organization is nonselective. Because of their higher degree of proficiency, the HPB community outperformed the LPB group in terms of performance and precision, enabling them to unlock terms and definitions in their $\mathrm{L} 1$ and $\mathrm{L} 2$.

\subsection{Comparison of performance of HPB \& LPB in L2 to L1 translation.}

The L2 to L1 translations are another differentiation to be made between the HPB and the LPB groups (backward). This analogy differs from the previous one in that the participants will be translating words from English (L2) to Arabic (L1), from their second to the native tongue. Since it is their second language, and all sets of participants are extremely knowledgeable, participants would have a greater chance of sharing their experiences. The proposed hypothesis for this section of the study is that the HPB and LPB classes' contribution in the translation from L2 to L1 is identical.

A statistical comparison of t-test on the RTs of HPB and LPB classes was used to make this comparison. The MRTs of highly fluent bilinguals were 1373.3, with an MSE of 66.61, and the LPB group was 1653.4, with an MSE of 47.894. In the translation condition L2 o L1, the MRTs of the HPB group is slightly quicker than the LPB group, $t(48)=-3.414, p=.0010 .05$. The second group's lower proficiency resulted in a slower response time than those with a high proficiency level. This implies that the disparity in success between the HPB and LPB groups is attributed to their greater proficiency in L2 comprehension and processing. The mean reaction time obtained by the highly proficient and low proficient groups is represented in Chart 4.10.

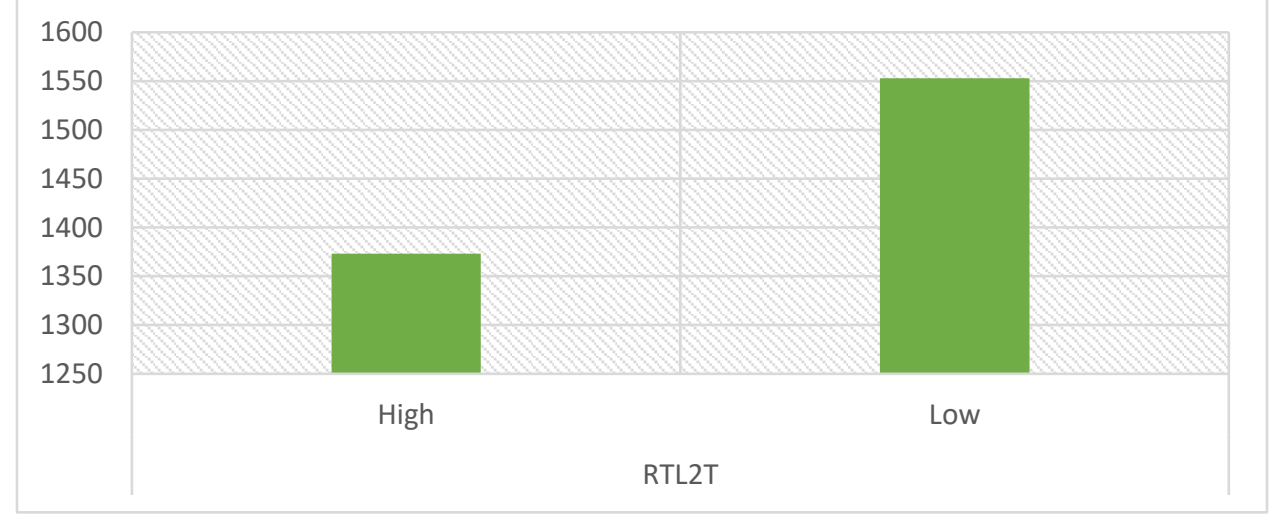

Chart 4.10. MRTs score of HPB Vs LPB in translation from L2 to L1. 
The mean of the correct responses was also computed in the second condition of the translation task. The accuracy rating for the HPB group was $98.08 \%$, while the rate for the LPB group was $79.40 \%$. As a result, the high proficient bilinguals scored more correctly than the low proficient bilinguals, and a comparative comparison was performed to demonstrate the important difference between the two classes in terms of correct answer rate. In terms of ACC, the t-test revealed a large gap between the two classes, $t(48)=11.206, p=.0010 .05$. The ACC comparison between classes is depicted in Chart 4.11.

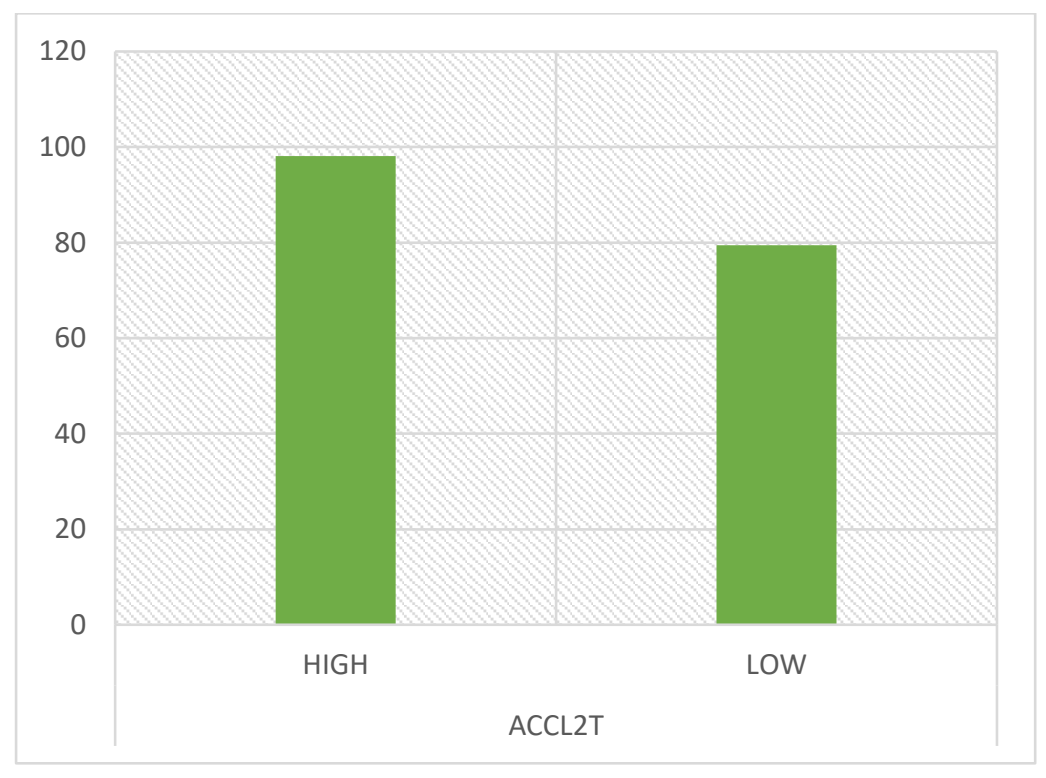

Chart 4.11.A comparison of ACC between HPB Vs LPB.

In the first condition ( $L 1 \circ \mathrm{L} 2)$ and the second condition (L1 $\circ \mathrm{L2})$, participants from both groups showed no difference in outcomes (L2 to L1). In both ways, they have demonstrated similar RTs and precision. In the translation tasks from L2 to L1, the HPB group outperformed the LPB group. The finding reached in this study was similar to that reached in the previous review, and it should be noted that proficiency level played a key role in achieving this outcome, as low-proficient bilinguals had a slower response time and lower accuracy than high-proficient bilinguals. Despite being asked to translate from their second language (L2) to their native language (L1), where they had more room to articulate meanings and find some other related meanings to the object, the low-proficient group performed equally well in both directions (L2 to L1) (stimuli). This analysis contradicts other researchers' findings who found that participants were better at translating $L 2$ to $L 1$ than $L 1$ to $L 2$.

According to Yuko Sakaki (2012), the HPB demonstrated a significant change in output when converting from L2 to L1, while the LPB showed no difference in performance. Despite the fact that they translated into their native language (L1), which is better than $L 2$, the high and low-proficient participants translated from L1 to $L 2$, in the same manner, they translated from $L 2$ to $L 1$. While there was a substantial difference between the high-proficient and low-proficient groups in each direction independently, there was no difference in response time or accurate responses when we compared their findings across directions. However, HPB outperformed LPB in both ways, indicating the importance of proficiency level in the lexical-semantic organization.

The low fluent bilinguals' response time was the same in both ways, with no major variations. It's worth noting that the semantic sense or translation direction has no bearing on the poor proficiency bilingual translation in this case. Bilinguals with a high level of proficiency outperformed bilinguals with a low level of proficiency in all areas. This means that when a person's lexical activation speed increases, so do his lexical activation speed. This also suggests that the word recognition process was carried out without the use of semantic logical link retrieval, relying solely on direct language associations (L1 and L2).

Second language proficiency affected the translation challenge in Arabic-English bilingual groups, as the more fluent group ranked slightly faster in L1 and L2 words than the less proficient bilinguals. The translation task indicated that HPB words in L1 and L2 had more direct lexical access and activation in both languages lexicons than words in the lexicons of less fluent bilinguals, whose lexicon displayed no direct correlation even after developing second language proficiency. The two groups showed localization similarity in the translation task, with translation latencies from L2 to L1 being equal in terms of RTs and ACC to those from L1 to L2. This similarity in translation is the polar opposite of what a previous study has discovered.

The RHM (Kroll and Stewart, 1994) was first proposed to describe established translational asymmetries between qualified bilinguals whose second language was acquired early in life and whose dominant language is their first. The underlying asymmetry in the frequency of the relations between words and concepts in each bilingual language, according to the RHM, is a

Page | 30 
longer reaction time from L1 to L2 (forward translation) than L2 to L1 (backward translation). The observations of this analysis refuted the proposed model hypothesis and corresponded to new hypotheses and projections of other models, such as BIA+. In both directions (L1 to $L 2$ and $L 2$ to $L 1$ ), the researchers observed no differences in translation performance, and the HPB and LPB groups performed equally in terms of RTs and ACC in both directions.

To analyze the Revised Hierarchical Model in this study, we can see that there was a statistical gap between HPB and LPB in both the first and second conditions of the translation assignment, and the result revealed translation asymmetry in both the high and low proficient bilingual groups. The findings of condition 1 confirm the notion of complex shifts within its architecture, and the data from the high proficient Arabic-English bilingual community fit the asymmetrical hierarchical paradigm of bilingual memory. According to the word association model, the lack of category-based translation activity in the less fluent community indicates that the translation process from English to Arabic does not access the semantic system. The reaction times and percentage of right responses received in the two directions are compared in Table 4.4.

\begin{tabular}{|c|c|c|c|c|c|c|c|}
\hline \multicolumn{2}{|c|}{ proficiency } & \multirow{3}{*}{$\begin{array}{l}N \\
25\end{array}$} & \multirow{3}{*}{$\begin{array}{l}\text { Mean } \\
1390.8 \\
272\end{array}$} & \multirow{3}{*}{$\begin{array}{c}\text { Std. } \\
\text { Deviation } \\
327.2376 \\
1\end{array}$} & \multirow{3}{*}{$\begin{array}{c}t \\
-4.306\end{array}$} & \multirow{3}{*}{$\begin{array}{l}\text { df } \\
48\end{array}$} & \multirow{3}{*}{$\begin{array}{l}\text { Sig. }(2- \\
\text { tailed) } \\
\quad .000\end{array}$} \\
\hline RT & High & & & & & & \\
\hline L1T & & & & & & & \\
\hline & Low & 25 & $\begin{array}{r}1699.8 \\
940\end{array}$ & $\begin{array}{r}147.3676 \\
4\end{array}$ & -4.306 & 33.350 & .000 \\
\hline \multirow[t]{2}{*}{$\begin{array}{l}\text { ACC } \\
\text { L1T }\end{array}$} & High & 25 & $\begin{array}{r}90.360 \\
0\end{array}$ & 3.32766 & 10.476 & 48 & .000 \\
\hline & Low & 25 & $\begin{array}{r}79.360 \\
0\end{array}$ & 4.06079 & 10.476 & 46.215 & .000 \\
\hline \multirow[t]{2}{*}{$\begin{array}{l}\text { RT } \\
\text { L2T }\end{array}$} & High & 25 & $\begin{array}{r}1273.2 \\
524\end{array}$ & $\begin{array}{r}333.0124 \\
3\end{array}$ & -3.414 & 48 & .001 \\
\hline & Low & 25 & $\begin{array}{r}1553.3 \\
460\end{array}$ & $\begin{array}{r}239.4696 \\
8\end{array}$ & -3.414 & 43.584 & .001 \\
\hline \multirow[t]{2}{*}{$\begin{array}{l}\text { ACC } \\
\text { L2T }\end{array}$} & High & 25 & $\begin{array}{r}91.080 \\
0\end{array}$ & 3.16122 & 11.206 & 48 & .000 \\
\hline & Low & 25 & $\begin{array}{r}83.400 \\
0\end{array}$ & 4.14327 & 11.206 & 44.870 & .000 \\
\hline
\end{tabular}

Chart 4.4: MRTs and ACC of HPB \& LPB Groups in both translation directions.

The table above explicitly shows the results of the previous study, and we can see that the HPB group's RTs did not vary from L1 to L2 (1390.8272 / $90.36 \%)$ or from L2 to L1 (1273.2524 / $91.08 \%)$, and their success was close in both directions. In both ways, the LPB category had no output variations (L1-RT 1699.8940 and ACC 79.3600). (L2-RT 1553.3460 and ACC 83.4000). While there are clear gaps between the classes of high and low fluent bilinguals, there is no gap in their success in the two directions, which is entirely contrary to the conventional perceptions of the models suggested previously.

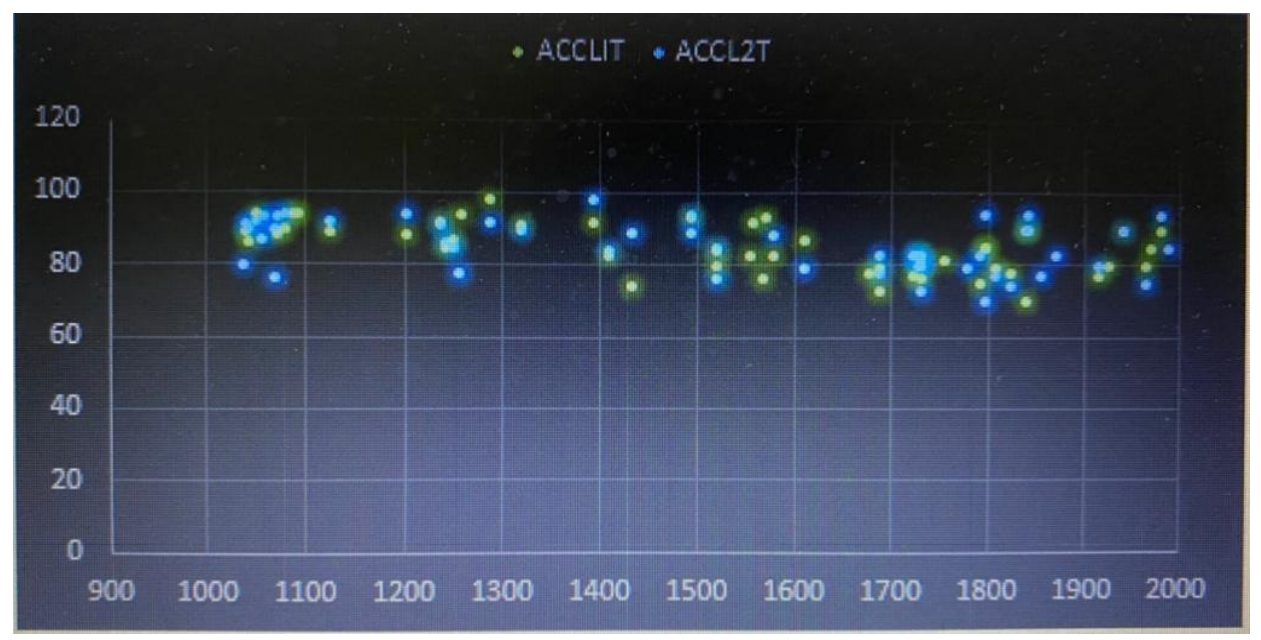

Chart 4.12: Distribution of participants in L1 Vs L2 in terms of RTs \& ACC. 
The above-mentioned rationale for the distribution of differences between high and low proficiency bilinguals implies a conceptual model of bilingual memory that varies greatly from the traditional dual-level lexico-conceptual model (Kroll, 1993; Kroll \& De Groot, 1997; Kroll \& Stewart, 1994). The model ignores the possibility of neural discrepancies between the two groups of participants in the two languages and treats a mental representation as a single, language-independent entity. Each language is said to have its own semantic network, which is strongly integrated and overlapping, and therefore each language's mental representation can be structured differently. This point of view is in line with recent advances in bilingual memory theory (Francis, 1999; Grosjean, 1998; Paradis, 1997; Pavlenko, 1999).

\section{Conclusion}

Bilingualism is a complex condition that is influenced by a variety of influences, such as language literacy and cultural context. Different degrees of proficiency in the second language can occur in a bilingual. A balanced bilingual is similarly fluent in both languages, while a dominant bilingual is more proficient in one of the languages. Balanced bilinguals are exceedingly rare in language communities. The mastery level is measured by comprehension, reading, and writing skills. The study's participants had varying degrees of second language proficiency, ranging from low to native-like control fluency. In L1 and L2, there was no significant gap in lexical-semantic processing performance between Groups I (HPB) and II (LPB). (Paradise, 1979). Many aspects affect language acquisition, including the participant's age at the time of the acquisition, the method of language learning, the degree of language competence, and the verbal similarities and differences between the two languages, to name a few. The output of lexical-semantic organization may have been influenced by each of these factors or their combination.

The study's first goal was to use translation tasks to explore the lexical-semantic organization of high and low fluent ArabicEnglish bilinguals. A formal mathematical interpretation of the study effects of different variables yielded this research's conclusions. In LI and L2, high proficient bilinguals' output was compared to that of low proficient bilinguals (HPB vs LPB). Individuals in group I outperformed those in Group II on any of the tasks used to study lexical-semantic organization. Individuals in Group II made more mistakes on translation assignments than those in group I, resulting in lower accuracy. The precision and reaction times of group II in $\mathrm{LI}$ were higher than those in $\mathrm{L} 2$, and the difference was limited to their proficiency level.

The first goal's result reflects the lexical-semantic organization of Arabic-English bilinguals. The importance of the proficiency component in the lexical-semantic organizing phase was shown by comparing the two classes of bilinguals. If a bilingual's proficiency increases, so do his or her response time and accuracy. In this sample, the bilingual population with high proficiency had faster response times and completed tasks more reliably than the group with low proficiency. In terms of response time and precision in both directions of the translation task, the low-proficient bilinguals did well. The high degree of natural language proficiency shared by both high and low-proficient groups in L2 to L1 was because they were both highly proficient in their mother tongue.

Models of the lexical-semantic organization say that the degree of lexical activation from L1 to L2 is not the same as the extent of lexical activation from L2 to L1. This is because there is a clear interaction between the items displayed and their conceptual interpretations in the bilingual shop. It means that bilingual translation from L2 to L1 is quicker and more reliable than bilingual translation from L1 to L2. Since L1 terms are more recognizable and commonly used in bilingual native languages, and these words have deep and immediate bilingual memory associations, this is the case. Despite a major difference in image naming performance between $L 1$ and $L 2$, there was no difference in lexical activation speed in the first direction from $L 1$ to $L 2$ and the second direction from L2 to L1 in this analysis.

Low proficient bilinguals had a lot of difficulties performing translation tasks in both directions, according to the study's results, so their response speed and accuracy were slower than the high proficient group. Another topic to be explored in this study is the association between bilinguals' response times and their accuracy rate when conducting tasks. The mathematical study used to determine this information revealed that reaction time and accuracy had a positive relationship. The more precise the response, the quicker the reaction time is, and vice versa.

\section{References}

[1] Bijeljac-Babic, R., Biardeau, A., \& Grainger, J. (1997). Masked orthographic priming in bilingual word recognition. Memory \& Cognition, 25, 447-457. doi:10.3758/BF03201121

[2] Blanco-Elorrieta, E., \& Pylkkanen, L. (2015). Brain bases of language selection: MEG evidence from Arabic-English bilingual language production. Frontiers in Human Neuroscience, 9, 27. doi:10.3389/fnhum.2015.00027

[3] Chee, M. W. (2006). Dissociating language and word meaning in the bilingual brain. Trends in Cognitive Sciences, 10, 527-529. doi:10.1016/j.tics.2006.09.009

[4] Clark, H. H. (1973). The language-as-fixed-effect fallacy: A critique of language statistics in psychological research. Journal of Verbal Learning and Verbal Behavior, 12, 335-359. http://dx.doi.org/10.1016/S0022-5371(73)80014-3 
[5] Coderre, E., \& Van Heuven, W. (2014). The effect of script similarity on executive control in bilinguals. Frontiers in Psychology, 5, 1070. doi:10.3389/.2014.01070

[6] Cohen, J. (1988). Statistical power analysis for the behavioral sciences (2nd Ed.). Hillsdale, N.J.: L. Erlbaum Associates.

[7] Colomé, A. (2001). Lexical activation in bilinguals' speech production: Language-specific or language-independent? Journal of Memory and Language, 45, 721-736. http://dx.doi.org/10.1006/jmla.2001.2793

[8] Costa, A. (2005). Lexical access in bilingual production. In J. Kroll \& A. De Groot (Eds.), Handbook of bilingualism (pp. 308-325). Oxford, UK: Oxford University Press.

[9] Costa, A., Miozzo, M., \& Caramazza, A. (1999). Lexical selection in bilinguals: Do words in the bilingual's two lexicons compete for selection? Journal of Memory and Language, 41, 365-397. http://dx.doi.org/10.1006/jmla.1999.2651

[10] Costa, A., \& Santesteban, M. (2004). Lexical access in bilingual speech production: Evidence from language switching in highly proficient bilinguals and L2 learners. Journal of Memory and Language, 50, 491-511. http://dx.doi.org/10.1016/j.jml.2004.02.002

[11] Crinion, J., Turner, R., Grogan, A., Hanakawa, T., Noppeney, U., Devlin, J. T., Aso, T., Urayama S., Fukuyama, H., Stockton, K. \& Usui, K. (2006). Language control in the bilingual brain. Science, 312(5779), 1537-1540. doi:10.1126/science.1127761

[12] Dalrymple-Alford, E. (1968). Interlingual interference in a color-naming task. Psychonomic Science, 10, 215-216. doi:10.3758/BF03331487

[13] Dijkstra, T. (2001). What we know about bilingual word recognition: A review of studies and models. In Plenary address at the international symposium on bilingualism.

[14] Dijkstra, T., Timmermans, M., \& Schriefers, H. (2000). On being blinded by your other language: Effects of task demands on interlingual homograph recognition. Journal of Memory and Language, 42, 445-464. http://dx.doi.org/10.1006/jmla.1999.2697

[15] Dijkstra, T., \& Van Heuven, W. J. B. (2002). The architecture of the bilingual word recognition system: From identification to decision. Bilingualism: Language and Cognition, 5, 175-97. https://doi.org/10.1017/\$1366728902003012

[16] Duyck, W., Van Assche, E., Drieghe, D., \& Hartsuiker, R. J. (2007). Visual word recognition by bilinguals in a sentence context: evidence for nonselective lexical access. Journal of Experimental Psychology: Learning, Memory, and Cognition, 33, 663. http://dx.doi.org/10.1037/02787393.33.4.663

[17] Duyck, W., Vanderelst, D., Desmet, T., \& Hartsuiker, R. (2008). The frequency effect in second-language visual word recognition. Psychonomic Bulletin \& Review, 15, 850-855. doi:10.3758/PBR.15.4.850

[18] Ethnologue: Languages of the world (2016). Catalan. Retrieved from https://www.ethnologue.com/language/cat

[19] Fishman, J. A. (1964). Language maintenance and language shift as a field of inquiry. A definition of the field and suggestions for its further development. Linguistics, 2, 32-70. https://doi.org/10.1515/ling.1964.2.9.32

[20] Fishman, J. A. (1965). Who speaks what language to whom and when?. La linguistique, 1(Fasc. 2), 67-88. http://www.jstor.org/stable/30248773

[21] Gerard, L. D., \& Scarborough, D. L. (1989). Language-specific lexical access of homographs by bilinguals. Journal of Experimental Psychology: Learning, Memory, and Cognition, 15, 305.

[22] Giles, H., Taylor, D. M., \& Bourhis, R. (1973). Towards a theory of interpersonal accommodation through language: Some Canadian data. Language in Society, 2, 177-192. https://doi.org/10.1017/S0047404500000701

[23] Grosjean, F. (1982). Life with two languages: An introduction to bilingualism. Harvard University Press.

[24] Grosjean, F. (2000). Processing mixed language: Issues, findings and models. In Li Wei (Ed.), The bilingual reader (1st edition) (pp. 443-469). London: Routledge

[25] Grosjean, F. (2013). Bilingualism: A short introduction. In F. Grosjean \& P. Li (Eds.), The psycholinguistics of bilingualism (pp. 5-25). New Jersey: Blackwell Publishing.

[26] Hernandez, A. E., Bates, E. A., \& Avila, L. X. (1996). Processing across the language boundary: A cross-modal priming study of SpanishEnglish bilinguals. Journal of Experimental Psychology: Learning, Memory, and Cognition, 22, 846-864. doi:10.1037/0278-7393.22.4.846

[27] Kaushanskaya, M., \& Marian, V. (2007). Bilingual language processing and interference in bilinguals: Evidence from eye tracking and picture naming. Language Learning, 57, 119-163. doi: 10.1111/j.1467-9922.2007.00401.x

[28] Kroll, J. F., Bobb, S. C., Misra, M., \& Guo, T. (2008). Language selection in bilingual speech: Evidence for inhibitory processes. Acta Psychologica, 128, 416-430. http://dx.doi.org/10.1016/j.actpsy.2008.02.001

[29] Kroll, J. F., \& Stewart, E. (1994). Category interference in translation and picture naming: Evidence for asymmetric connections between bilingual memory representations. Journal of Memory and Language, 33, 149.

[30] Liepmann, D. \& Saegert, J. (1974). Language tagging in bilingual free recall. Journal of Experimental Psychology, 103, $1137-1141$. http://dx.doi.org/10.1037/h0037403

[31] Li Heij, W. (2005). Selection processes in monolingual and bilingual lexical access. In J. Kroll \& A. De Groot (Eds.), Handbook of bilingualism (pp. 289-307). Oxford, UK: Oxford University Press.

[32] Mahboob, A., \& Elyas, T. (2014). English in the Kingdom of Saudi Arabia. World Englishes, 33, 128-142. doi:10.1111/weng.12073

[33] Marian, V., Blumenfeld, H. K., \& Boukrina, O. V. (2008). Sensitivity to phonological similarity within and across languages. Journal of Psycholinguistic Research, 37, 141-170. doi:10.1007/s10936-007-9064-9

[34] Marian, V., \& Spivey, M. (2003). Competing activation in bilingual language processing: Within-and between-language competition. Bilingualism: Language and Cognition, 6, 97-115. https://doi.org/10.1017/S1366728903001068

[35] Marian, V., Spivey, M., \& Hirsch, J. (2003). Shared and separate systems in bilingual language processing: Converging evidence from eye tracking and brain imaging. Brain and Language, 86, 70-82. doi:10.1016/S0093-934X(02)00535-7

[36] News on the Web Corpus. (2016). Corpus of Contemporary American English. Retrieved from http://corpus.byu.edu/now/

[37] Ojemann, G. A., \& Whitaker, H. A. (1978). The bilingual brain. Archives of Neurology, 35, 409-412. doi:10.1001/archneur.1978.00500310011002

[38] Poulisse, N. \& Bongaerts, T. (1994). First language use in second language production. Applied Linguistics, 15, 36-57. https://doi.org/10.1093/applin/15.1.36

[39] Psychology Software Tools, Inc. [E-Prime 2.0]. (2012). Pittsburg, PA. Retrieved from http://www.pstnet.com 
[40] Roelofs, A., Piai, V., Garrido Rodriguez, G., \& Chwilla, D. (2016). Electrophysiology of cross-language interference and facilitation in picture naming. Cortex: A Journal Devoted to the Study of the Nervous System and Behavior, 76, 1-16.

[41] Saegert, J., Obermeyer, J. \& Kazarian, S. (1973). Organizational factors in free recall of bilingually mixed lists. Journal of Experimental Psychology, 97, 397-399.

[42] Sahgal, A. (1991). Patterns of language use in a bilingual setting in India. In J. Cheshire (Ed.), English around the world: Sociolinguistic perspectives (pp. 299-306) Cambridge University Press.

[43] Sebba, M. (2011). Societal bilingualism. In R. Wodak, B. Johnston, \& P. E. Kerswill (Eds.), The SAGE handbook of sociolinguistics (pp. 445-459). Los Angeles, London: Sage Publications.

[44] Siachitema, A. (1991). The social significance of language use and language choice in a Zambian urban setting: An empirical study of three neighbourhoods in Lusaka. In J. Cheshire (Ed.), English around the World (pp. 474-90). Cambridge University Press.

[45] Toothaker, L. E., \& Miller, L. (1996). Introductory statistics for the behavioral sciences. Pacific Grove, CA: Thomson Brooks/Cole Publishing Co.

[46] Van Heuven, W. J., Dijkstra, T., \& Grainger, J. (1998). Orthographic neighborhood effects in bilingual word recognition. Journal of Memory and Language, 39, 458-483. 